\title{
Correction to: Induced surface proteins of Staphylococcus epidermidis adhering to titanium implant substrata
}

\author{
R. Bürgers ${ }^{1}$ (I) $\cdot$ C. Morsczeck ${ }^{2} \cdot$ O. Felthaus ${ }^{2} \cdot$ M. Gosau ${ }^{2} \cdot$ H. C. Beck ${ }^{3} \cdot$ T. E. Reichert ${ }^{2}$
}

Published online: 26 March 2019

(C) Springer-Verlag GmbH Germany, part of Springer Nature 2019

Correction to: Clinical Oral Investigations 22(7): 2663-2668 https://doi.org/10.1007/s00784-018-2508-9

There is a mistake in the original published version of this article. The word 'Streptococcus' in the article title should have been 'Staphylococcus'.

Publisher's note Springer Nature remains neutral with regard to jurisdictional claims in published maps and institutional affiliations.

The online version of the original article can be found at https://doi.org/ 10.1007/s00784-018-2508-9

\footnotetext{
R. Bürgers

ralf.buergers@med.uni-goettingen.de
}

1 Department of Prosthodontics, UniversityMedical Center Göttingen, Robert-Koch-Strasse 40, 37075 Göttingen, Germany

2 Department of Oral and Maxillofacial Surgery, University Hospital, Regensburg, Franz-Josef Strauss Allee 11, 93053 Regensburg, Germany

3 Department of Clinical Biochemistry and Pharmacology, Centre for Clinical Proteomics, Odense University Hospital,

DK-5000 Odense, Denmark 